\title{
CENTRO MÁRIO SCHENBERG DE DOCUMENTAÇÃO DE PESQUISA EM ARTES
}

Raras vezes o pensamento estético desenvolvido no Brasil foi tão longe, utilizando paralelos profundos, emergindo de correlações remotas ou saltando do presente às culturas primitivas.

Procurando explicar as suas reflexões, Mário Schenberg declara-se marcado por uma visão de "novo humanismo", envolvendo a Ciência e a Arte. Afirma ter recebido influências do pensamento oriental, da visão fantástica, ao mesmo tempo em que admira as idéias mais avançadas da Física e da mídia. Mantém contatos com as vanguardas de seu tempo e com a obra de arte, vista não como representação direta da nature$\mathrm{za}$, mas como objeto imerso no universo. Não se dedica ao desmantelamento da estética tradicional; procura uma visão da Arte inserida na concepção mais abrangente da cultura.

Suas críticas de arte, ainda que não sistematizadas, constituem fonte importante para o conhecimento de sua visão de mundo. Abrange o conhecimento e a prática de

\section{A AUTORA}

Elza Maria Ajzenberg

Professora Titular do Departamento de Comunicações e Artes da ECA-USP e Coordenadora do Projeto Mário Schenberg. vários setores, sendo de uma curiosidade intelectual incessante, aberto a uma variedade de experiências, a exemplo dos mestres renascentistas.

O conjunto de sua obra é importante e complexo, estando ainda por ser melhor estudado e divulgado. Seus interesses vão da Física teórica à atuação política como deputado; da vivência universitária às campanhas pedagógicas e do "Petróleo é nosso"; da divulgação da Arte ao júri da Bienal Internacional.

$\mathrm{Na}$ área da Arte, no Brasil, envolve-se com vários movimentos e grupos, atuando com freqüência no campo da crítica de Arte. Elabora significativo acervo da documentação a respeito de artistas, tais como Volpi, Flávio de Carvalho, Portinari, Waldemar Cordeiro, Mário Gruber, João Rossi, Aguilar, Maurício Nogueira Lima, Tozzi. Os seus textos analisam a importante evolução na História da Arte Brasileira nos anos 50 a 80.

São de especial importância, nos anos 60, os estudos sobre Arte e Tecnologia e sobre os Movimentos Concretista e Neoconcretista. Naqueles anos, envolve-se ainda com a organização de salas especiais da Bienal Internacional de São Paulo e do Júri Nacional de Seleção. As alterações políticas e culturais desse período fomentam maior engajamento, mas não se pode perder de vista que, com o recrudescimento político, 
Mário, apesar de punido pela ditadura $^{1}$, consegue prosseguir com o fomento artístico. Ao lado dos estudos vanguardistas, escreve vários textos referentes à Arte Mágica, enquanto coleciona significativo acervo de Arte Primitiva.

Na série de textos dos anos $\mathbf{5 0}$, 60,70 e 80, procura justamente deixar pistas para uma adequação de mensagens às suas reflexões acerca da Filosofia da Ciência. Tal vontade encontra eco nas deduções estéticas que ditam sempre o valor da criatividade, da fantasia e da intuição como capacidades da apreensão e conhecimento.

Outra ponte traçada é com a contemporaneidade e o mundo internacional. Por trás, estão as lições que retira do Novo Realismo que "está profundamente influenciado pelos meios de comunicação de massa; cartazes, cinema,

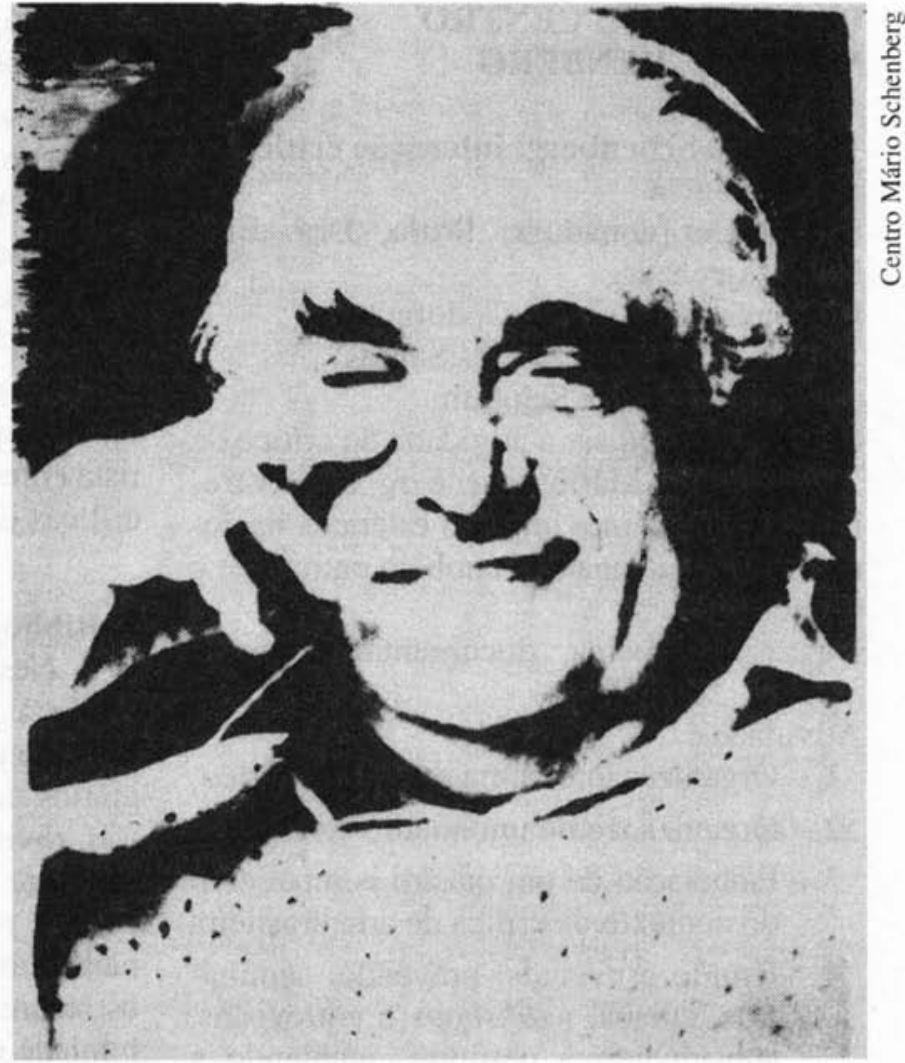

Mário Schenberg, físico, crítico de arte, político: um homem de seu tempo, ligado às lutas do povo brasileiro pela Soberania Nacional. televisão, história em quadrinhos.

$\mathrm{O}$ novo realismo brasileiro filia-se naturalmente às grandes correntes atuais do movimento neo-realista internacional. Por outro lado, tem suas características próprias, determinadas pelas condições econômicas, sociais e culturais brasileiras" 2 . Este movimento ganha repercussão no Brasil, em 1965, depois de já ter marcado as artes plásticas, dois ou três anos antes, nos maiores centros internacionais. Vários outros momentos e artistas são valorizados em seus textos como participantes de um mundo além das fronteiras do

país. Neste sentido é importante a sua participação junto à Bienal.

A interpretação do significado de seu trabalho leva à construção de uma arte que trabalha oposições moderno/arcaico; contemporâneo/primitivo; às vezes mais especificamente à "diluição de uma questão mágica" que perpassa as obras. Dele pode-se concluir que a leitura de uma obra de arte deve ser sempre entendida mais como necessidade de o artista refletir estados universais que a intuição artística (ou a científica) pode captar.

1. O Ato Institucional n? 5 revogava os direitos civis. Essa determinação ocasionou o expurgo dos órgãos públicos de pessoas não coniventes com o governo militar. Em 28 de abril de 1969, a USP era atingida. Um decreto datado de 25 de abril resolveu aposentar "nos cargos que ocupam nos órgãos da Administração Pública Federal" 42 pessoas. Entre diversos intelectuais, estavam os professores: Florestan Fernandes, Janime Tiomno e João Batista Villanova Artigas. Um segundo decreto, baixado no dia 29 de abril de 1969, aposentava ou demitia mais 23 pessoas, entre elas, Mário Schenberg. Daí por diante, o Professor Schenberg se tornaria um "exilado em sua própria terra". Sendo submetido a inquérito, refugia-se em casas de amigos, sem poder exercer sua função acadêmica.

2. CAMPOS, Haroldo. O universalismo de Schenberg. Jornal da USP. 30/abr-05/mai/1994. p.9. 


\section{PROJETOS DO CENTRO MÁRIO SCHENBERG}

\section{Projeto Schenberg: interação crítica de arte e ciência}

Equipe-Coordenadora: Profa. Dra. Elza Maria Ajzenberg

Docentes: Ilo Zemma Codofnotto

Salvina M. dos Santos

Suzana Schmith

Objetivo: Pesquisar a atividade do crítico de arte Mário Schenberg, suas correlações com os movimentos estéticos nacionais e internacionais; e também entre Arte e Ciência.

Natureza: Artística, documental e tecnocientífica

Atividades:

1 - Organização de uma quadro histórico

2 - Organização de um quadro estatístico

3 - Elaboração de um quadro comparativo do contexto da crítica de arte brasileira

4 - Estudo e eventos, prevendo: seminários, cursos, workshops e entrevistas, subsidiando a pesquisa, mantendo a correlação entre arte e ciência

Síntese: Visa examinar Mário Schenberg como crítico de arte e sua influência no universo mais amplo da crítica de arte brasileira Projeto financiado pelo $\mathrm{CNPq}$ (Conselho Nacional de Desenvolvimento Científico e Tecnológico) e bolsistas financiados pelo FUNDAP e CNPq

\section{Projeto Banco de Dados}

Equipe-Coordenadora: Profa. Dra. Elza Maria Ajzenberg

Docente: Alessandra Matias de Oliveira

Natureza: Artística, documental e tecnocientífica

Período: de novembro de 1994 a novembro de 1995

Atividades:

1 - Pesquisa no arquivo das críticas: identificar e classificar os textos, elaborar resenhas e resumos, implanta- ção do programa de banco de dados, catalogação e digitação dos textos

2 - Pesquisa dos artistas: realizar listagens de artistas, elaborar resumos biográficos, catalogação e digitação

3 - Pesquisa de outras informações: busca de dados, elaborar resenhas, catalogação

Síntese: $O$ projeto consiste na inclusão da biografia e currículo artístico de cada artista enfocado por Mário Schenberg em suas críticas de arte

\section{Bibliografia Brasileira das Artes}

Nesta primeira etapa, o projeto restringiu-se à produção artística dos docentes da ECA no período entre 1989 e 1992 . Os estagiários da FUNDAP resumiram esta produção, dividindo-a em assuntos e distribuindo -os entre si, para facilitar o trabalho.

A relação desta produção foi baseada na Bibliografia dos Docentes da ECA-USPe os resumos foram feitos segundo a disponibilidade dos textos no acervo da Faculdade. Os que não foram encontrados eram solicitados aos seus respectivos autores, que nem sempre puderam nos atender. Algumas produções, portanto, estão sem resumo.

Cabe mencionar a inestimável colaboração da Biblioteca da ECA, em conjunto com a qual este trabalho foi realizado, dos professores Lorenzo Mammi, Antônio Januzelli, Domingos T. Chiarelli e da artista plástica Alice Brill, que muito nos auxiliaram na revisão dos textos.

Além dos resumos de teses, livros e artigos de periódicos, inclui-se na bibliografia a indicação de catálogos, partituras, fitas, vídeos e filmes.

\section{Projeto Criatividade}

Visa dar mais organicidade às atividades desenvolvidas pelo Centro Mário Schenberg através de reflexões da conceituação do processo criativo. Propõe a reali- 
zação de eventos, como seminários, cursos, debates, congressos, workshops, preparação de publicações etc.

\section{Projeto Criatividade/ Brincando com Arte - 1995}

Tem como proposta incentivar a criatividade através de atividades plásticas, desenvolvidas pelas crianças do Centro Comunitário São Francisco de Assis (Bela Vista), procurando deixar emergir imagens vividas pelas próprias crianças diante de um universo recortado pelas mesmas. Imaginação, sensibilidade e liberdade constituíram alvo das atenções do trabalho já realizado.

\section{Congresso Arte e Ciência}

Previsto para os dias 25,26 e 27 do mês de outubro de 1995 . Visa investigar as correlações existentes entre pesquisadores renomados nas duas áreas através de workshop, exposições, palestras, seminários, mesas-redondas e diversas discussões que abarquem o tema. Simultaneamente será realizado o VI Seminário Mário Schenberg, evento realizado pelo Centro Mário Schenberg anualmente, desde 1990.

O Centro Mário Schenberg de Documentação da Pesquisa em Artes está localizado na Av. Lúcio Martins Ródrigues, 443, Bloco 9 sala 9, fone (011) $818.4022 \mathrm{e}$ você também pode participar. 